Gut, 1969, 10, 1029-1030

\title{
Influence of age and ABO blood groups in the precipitation of bleeding peptic ulcers
}

\author{
M. BERG \\ From the Division of Gastroenterology, Department of Medicine, Michael Reese Hospital and \\ Medical Center, Chicago, Illinois
}

SUMMARY In a series of patients admitted to hospital for bleeding duodenal ulcer, the mean age at onset for patients belonging to blood group $\mathrm{O}$ was significantly lower than for those of blood group A. This raises the question of the significance of age and ABO blood group substances in increasing the liability to, or protecting against, bleeding.

Since Aird, Bentall, Mehigan, and Roberts (1954) discovered an association between blood groups and a liability to develop peptic ulcer there have been numerous confirmations from all parts of the world. In 34 of 40 reports summarized by McConnell (1966), there is a significant excess of group $O$ in the duodenal ulcer patients compared with the controls, and in concurring gastric and duodenal, and antral ulcer, the same excess of group $\mathrm{O}$ as in duodenal ulcer is found. Group $\mathbf{O}$ patients with either gastric or duodenal ulcers are more likely to suffer from bleeding than are those of other groups (Langman and Doll, 1965). This significantly higher incidence of group $\mathrm{O}$ in subjects with bleeding duodenal ulcer than in those with uncomplicated ulcer is also reported for perforation, and the relationship may be with the severity of the ulcer pathology (Horwich, Evans, McConnell, and Donohoe, 1966). While data for duodenal ulcer patients failed to provide any evidence that the age at onset of symptoms or the age at operation was likely to be earlier among group $\mathrm{O}$ subjects (Doll, Swynnerton, and Newell, 1960), a number of years may elapse before the development of the more severe complications, of haemorrhage and perforation. In the present study, it was thought worthwhile to investigate the relationship between the ABO blood groups and the age at onset of bleeding in patients with haemorrhage due to gastric or duodenal ulcer, and to determine whether these substances played some part in producing or protecting against this complication.

RESULTS

Case records were collected of patients who were admitted to Michael Reese Hospital between 1961 and 1969 with a diagnosis of moderate to severe gastric or duodenal ulcer haemorrhage, and whose blood groups were recorded. It is only in the group with duodenal haemorrhage that adequate data are available for statistical analysis. The controls for blood groups were blood donors from the same locality. The ABO blood group distribution in patients with duodenal haemorrhage and in controls is seen in Table I. The difference noted between the

TABLE 1

ABO BLOOD GROUP DISTRIBUTION IN PATIENTS WITH DUODENAL ULCER HAEMORRHAGE AND CONTROLS

\begin{tabular}{|c|c|c|}
\hline Blood Group & Patients & Controls \\
\hline $\begin{array}{r}\mathbf{O} \\
\mathbf{A} \\
\mathbf{B} \\
\mathbf{A B}\end{array}$ & $\begin{array}{r}92(48.4 \%) \\
61(32.1 \%) \\
31(16.3 \%) \\
6(3.2 \%) \\
190(100 \%)\end{array}$ & $\begin{array}{rr}2,475 & (45 \%) \\
2,200 & (40 \%) \\
550 & (10 \%) \\
275 & (5 \%) \\
5,500 & (100 \%)\end{array}$ \\
\hline
\end{tabular}

blood type frequencies of the patients and the controls is significant $\left(\chi^{2} 11 \cdot 78\right.$ with 3 degrees of freedom, $P<0.02$ ). While the number in group $O$ is somewhat larger than in the controls, an unusual feature is the greater frequency of group B in the controls which differs from that reported in a number of series (McConnell, 1966).

The age distribution in the $\mathrm{ABO}$ blood groups at the onset of haemorrhage (SE t 0.05) is shown in Fig. 1, and the mean age values (SE t 0.05) are shown in Table II. The mean age for group $O$ is less than for group A but the variance is similar.

In Table III, the differences of the mean age values for the various $A B O$ blood groups tested by Student's $t$ test are shown. The value for the 


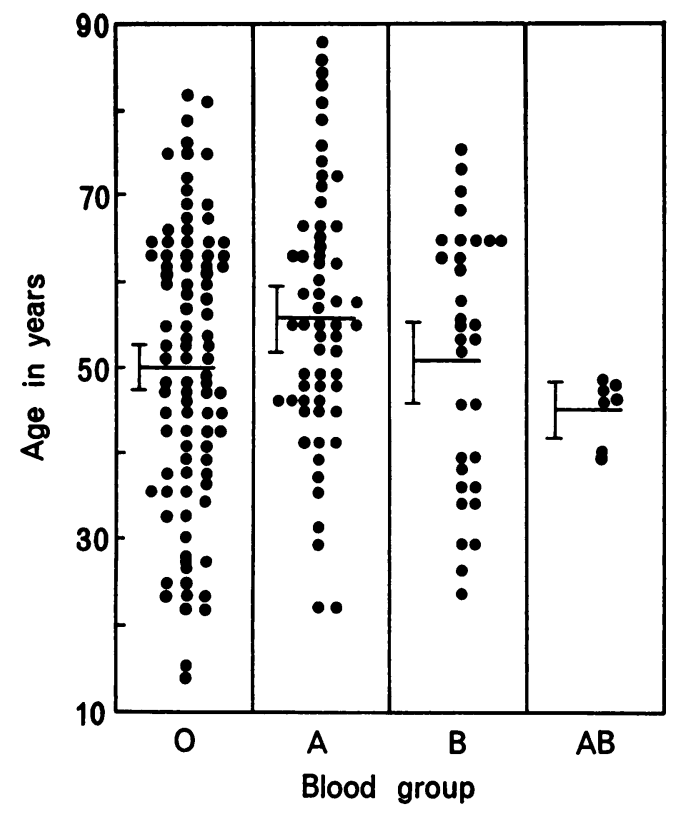

FIG. 1. Age distribution at the onset of duodenal haemorrhage related to $A B O$ blood groups. The horizontal bars indicate the mean and the vertical bars indicate standard error times (SEt 0.05).

\section{TABLE II}

RELATION BETWEEN MEAN AGE AND ABO BLOOD GROUPS AT ONSET OF HAEMORRHAGE ${ }^{1}$

\begin{tabular}{llllll} 
Blood Group & & & & $\begin{array}{l}\text { Combined } \\
A+B+A B\end{array}$ \\
\cline { 1 - 1 } & $A$ & $B$ & $A B$ & \\
\hline
\end{tabular}
\begin{tabular}{llllll}
\hline Mean age & $50.5 \pm 3.3$ & $56.5 \pm 3.8$ & $51.5 \pm 5.5$ & $46.7 \pm 2.9$ & $54.3 \pm 2.9$ \\
No. of & &
\end{tabular}

$\begin{array}{llllll}\text { cases } & 92 & 61 & 31 & 6 & 98\end{array}$

1Mean \pm SE t 0.05

\section{TABLE III}

COMPARISON OF DIFFERENCES IN MEAN AGES AND BLOOD GROUPS AT ONSET OF HAEMORRFIAGE

Group Comparisons

\begin{tabular}{|c|c|c|}
\hline Group Comparisons & $t$ & $\boldsymbol{P}$ \\
\hline $\begin{array}{ll}\mathbf{O} \text { vs } & \mathbf{A} \\
\mathbf{B} \\
\mathbf{A B} \\
(\mathbf{A}+\mathbf{B}+\mathbf{A B}) \\
\mathbf{A} \text { vs } & \mathbf{B} \\
& \mathbf{A B} \\
\mathbf{B} \text { vs } & \mathbf{A B}\end{array}$ & $\begin{array}{r}2 \cdot 36 \\
0 \cdot 28 \\
-0.60 \\
-1 \cdot 71 \\
1.54 \\
-1.60 \\
0.77\end{array}$ & $\begin{array}{l}<0 \cdot 02 \\
\text { NS } \\
\text { NS } \\
\text { NS } \\
\text { NS } \\
\text { NS } \\
\text { NS }\end{array}$ \\
\hline
\end{tabular}

difference in the mean ages at the onset of haemorrhage for groups $\mathrm{O}$ and $\mathrm{A}$ is statistically significant ( $\mathrm{P}<0.02)$.

\section{DISCUSSION}

The possible relationship between genetic factors and the natural history of peptic ulcer has been the subject of a number of reports, as has the association between blood group $\mathbf{O}$ and the liability to bleed. While the weight of evidence is in favour of both hereditary (ABO blood group and secretor status) and environmental factors playing a part in the development of bleeding duodenal ulcer, on the basis of our data it is suggested that the blood group substances may be of some significance in producing or in protecting against this complication as manifested by the age of onset. The mean age at onset of haemorrhage in the group $O$ patients was significantly lower than in group A $(P<0.02)$, indicating a greater susceptibility to bleed at an earlier age in $O$ group patients than in those in group $A$. Comparison of $\mathrm{O}$ with $\mathrm{B}, \mathrm{AB}$, or with the combined three remaining groups $(A+B+A B)$ was not significant. Since groups $B$ and AB in our series are relatively small and the reported results of large series (Horwich et al, 1966; Langman and Doll, 1965; Merikas, Christakopoulos, and Petropoulos, 1966) all suggest that patients of groups $B$ and $A B$ are like those of $\mathbf{A}$, that is, less susceptible to bleeding than those of group $\mathrm{O}$, this finding may be due to chance or to smaller differences and thus require the collection of a larger series for clarification.

I acknowledge the help of $\mathrm{Dr} \mathrm{H}$. Necheles, Dr G. Hutchinson, and Dr R. Jenkins for help with statistics, Dr A. Josephson of our Blood Center for permission to use their data on blood groups, and Mrs Mosier of the Medical Records Department for supplying data.

Supported by Medical Research Institute, grant no. 68-19.

\section{REFERENCES}

Aird, I., Bentall, H. H., Mehigan, J. A., and Roberts, J. A. F. (1954). The blood groups in relation to peptic ulceration and carcinoma of colon, rectum, breast and bronchus. An association between the ABO blood groups and peptic ulceration. Brit. med J., 2, 315-321.

Doll, R., Swynnerton, B. F., and Newell, A. C. (1960). Observations on blood group distribution in peptic ulcer and gastric cancer. Gut, 1, 31-35.

Horwich, L., Evans, D. A. P., McConnell, R. B., and Donohoe, W. T. A. (1966). ABO blood groups in gastric bleeding. Gut, 7, 680-685.

Langman, M. J. S., and Doll, R. (1965). ABO blood group and secretor status in relation to clinical characteristics of peptic ulcers. Gut, 6, 270-274.

McConnell, R. B. (1966). The genetics of gastrointestinal disorders, pp. 76-105, Oxford University Press, London.

Merikas, G., Christakopoulos, P., and Petropoulos, E. (1966). Distribution of ABO blood groups in patients with ulcer disease. Amer. J. dig. Dis., 11, 790795. 